Required software to e-Annotate PDFs: Adobe Acrobat Professional or Adobe Reader (version 11 or above). (Note that this document uses screenshots from Adobe Reader DC.)

The latest version of Acrobat Reader can be downloaded for free at: http://get.adobe.com/reader/

Once you have Acrobat Reader open on your computer, click on the Comment tab (right-hand panel or under the Tools menu).

This will open up a ribbon panel at the top of the document. Using a tool will place a comment in the right-hand panel. The tools you will use for annotating your proof are shown below:

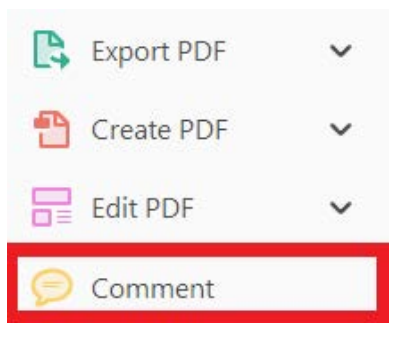

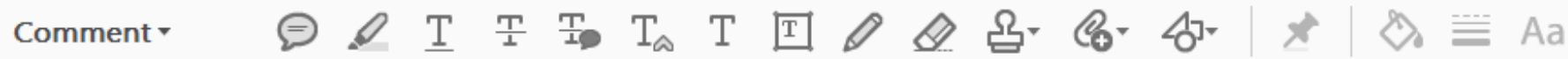

1. Replace (Ins) Tool - for replacing text.

T. Strikes a line through text and opens up a text box where replacement text can be entered.

How to use it:

- Highlight a word or sentence.

- Click on $\frac{T}{\perp P}$

- Type the replacement text into the blue box that appears.

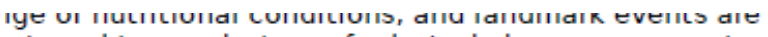
nitored in nonulations of relatively homogeneous single $n$ of secharomyes , and is initlated atter

: carbon source [ ] 1]. S:

are referred to as mei

$\mathrm{n}$ of meiosis-specific $\mathrm{s}$

inducer of meiosis) [3

I functions as a

repression, the repre

pression) and RGRI

rase II mediator subur

resem dil in

irectly or indirectly re
Reply X

staddon

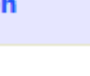

Reply $\mathbf{x}$

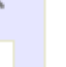

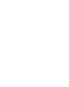

\section{SIf 05}

3. Commenting Tool - for highlighting a section to be changed to bold or italic or for general comments.

Use these 2 tools to highlight the text
where a comment is then made.

How to use it:

- Click on .

- Click and drag over the text you need to highlight for the comment you will add.

- Click on $\risingdotseq$.

- Click close to the text you just highlighted.

- Type any instructions regarding the text to be altered into the box that appears.

nformal invariance: $r$

A: Math. Gen., Vol. 12, N This needs to be bold

lified theory for a matri: 'ol. 8, 1984, pp. 305-32 ıd manuscript, 1984.

shing fractions for $\mathrm{DO} \rightarrow \mathrm{K}+\mathrm{K}$

nlation in nn Norave' Dhwe
2. Strikethrough (Del) Tool - for deleting text.

\section{T Strikes a red line through text that is to be}

How to use it:

- Highlight a word or sentence.

- Click on $\frac{T}{\perp}$.

- The text will be struck out in red.

experımental data It avallable. ror URrs to be had to meet all of the following criteria:

1. Small size (35-250 amino acids).

2. Absence of similarity to known proteins.

3. Absence of functional data which could n the real overlapping gene.

4. Greater than $25 \%$ overlap at the $\mathrm{N}$-termir terminus with another coding feature; ov $\epsilon$ both ends; or ORF containing a tRNA.

4. Insert Tool - for inserting missing text at specific points in the text.

\section{T Marks an insertion point in the text and} opens up a text box where comments can be entered.

How to use it:

- Click on $\mathrm{T}_{\boldsymbol{A}}$.

- Click at the point in the proof where the comment should be inserted.

- Type the comment into the box that appears.

Meiosis has a central role in the sexual reproduction of nearly all eukaryotes analysis of meiosis, esp jstaddon by a simple change of $n$ jeds conveniently monitored Yeast, is sin cells. Sporulation of Sat ne tyl

cell, the $\mathrm{a} / \alpha$ cell, and is of a fermentable carbor sporulation and are refe 2b]. Transcription of me meiosis, in S. cerevisiae of the

of the gene RMEI funct $\quad 05 / 05 / 2017$ 15:57
Rmelp to exert repressi of GALI gene expression) and $R G K I$ are required $[1,2,3,1]$. I nese $g \in$ 
5. Attach File Tool - for inserting large amounts of text or replacement figures.

Q. Inserts an icon linking to the attached file in the appropriate place in the text.

How to use it:

- Click on $\&$.

- Click on the proof to where you'd like the attached file to be linked.

- Select the file to be attached from your computer or network.

- Select the colour and type of icon that will appear in the proof. Click OK.

The attachment appears in the right-hand panel.

:hondrial preparatior ative daitage injury le extent of membra I, malondialdehyde ( (TBARS) formation. '

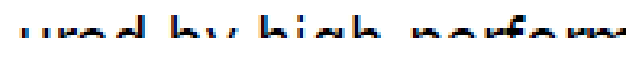

6. Add stamp Tool - for approving a proof if no corrections are required.

$\Omega=$ Inserts a selected stamp onto an appropriate place in the proof.

\section{How to use it:}

- Click on $\Omega$.

- Select the stamp you want to use. (The Approved stamp is usually available directly in the menu that appears. Others are shown under Dynamic, Sign Here, Standard Business).

- Fill in any details and then click on the proof where you'd like the stamp to appear. (Where a proof is to be approved as it is, this would normally be on the first page).

of the pusiness cycie, starting with the on perfect competition, constant ret

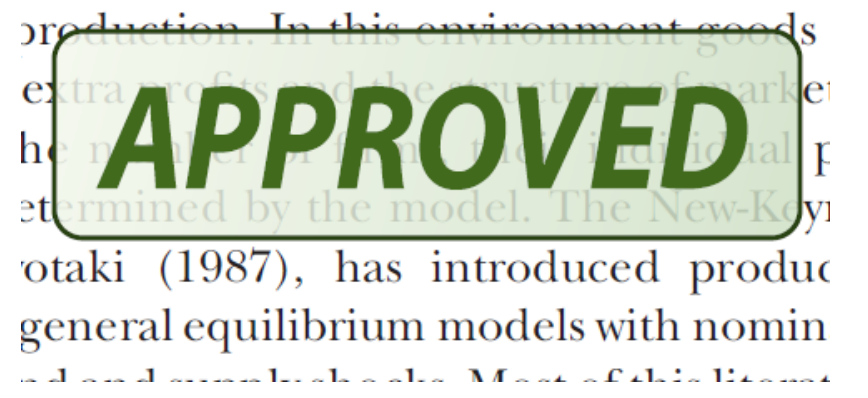

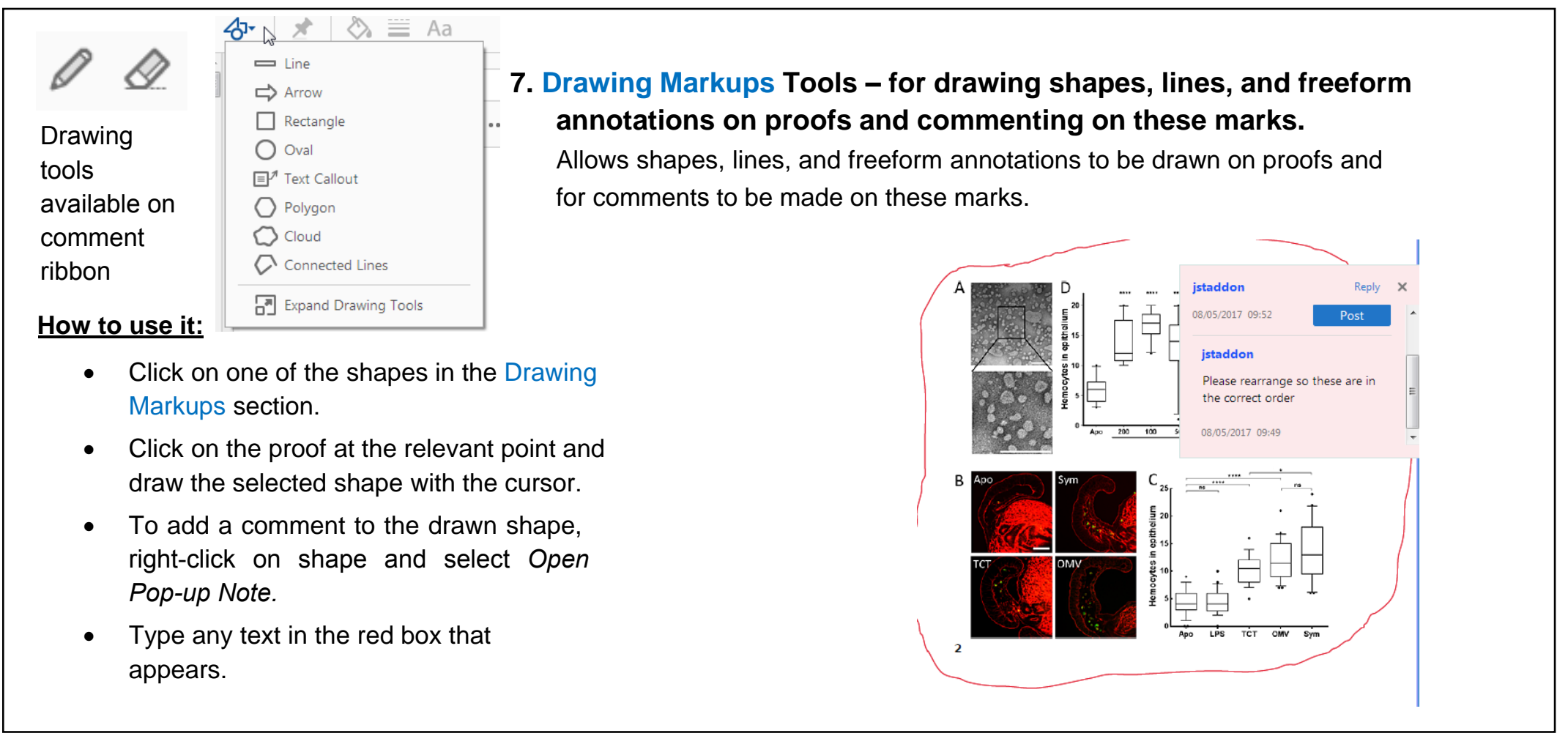

For further information on how to annotate proofs, click on the Help menu to reveal a list of further options:

\begin{tabular}{|c|c|c|}
\hline \multicolumn{3}{|l|}{ Help } \\
\hline & $\underline{\text { Online Support }}$ & $\mathrm{F} 1$ \\
\hline \multicolumn{3}{|c|}{ Welcome... } \\
\hline$?$ & Learn Adobe Acrobat Reader DC... & \\
\hline & About Adobe Acrobat Reader DC... & \\
\hline & About Adobe Plug-Ins... & \\
\hline & Generate System Report... & \\
\hline & Rẹpair Installation & \\
\hline & Check for Updates... & \\
\hline
\end{tabular}




\section{Author Query Form}

\section{Journal: Health Economics}

\section{Article: hec_3626}

Dear Author,

During the copyediting of your paper, the following queries arose. Please respond to these by annotating your proofs with the necessary changes/additions.

- If you intend to annotate your proof electronically, please refer to the E-annotation guidelines.

- If you intend to annotate your proof by means of hard-copy mark-up, please use the standard proofing marks. If manually writing corrections on your proof and returning it by fax, do not write too close to the edge of the paper. Please remember that illegible mark-ups may delay publication.

Whether you opt for hard-copy or electronic annotation of your proofs, we recommend that you provide additional clarification of answers to queries by entering your answers on the query sheet, in addition to the text mark-up.

\begin{tabular}{|c|c|c|}
\hline Query No. & Query & Remark \\
\hline Q1 & $\begin{array}{l}\text { AUTHOR: Please confirm that forenames/given names (red) and surnames/family } \\
\text { names (green) have been identified correctly. }\end{array}$ & \\
\hline Q2 & AUTHOR: Please verify that the linked ORCID identifiers are correct for each author. & \\
\hline Q3 & AUTHOR: Please check that authors' affiliations are correct. & \\
\hline Q4 & AUTHOR: Please check that keywords are correct. & \\
\hline Q5 & $\begin{array}{l}\text { AUTHOR: "Although choice experiments..." This sentence has been reworded for } \\
\text { clarity. Please check and confirm it is correct. }\end{array}$ & \\
\hline Q6 & $\begin{array}{l}\text { AUTHOR: Ref. "Ryan et al. (2009)" is cited in text but not provided in the reference } \\
\text { list. Please provide details in the list or delete the citation from the text. }\end{array}$ & \\
\hline Q7 & $\begin{array}{l}\text { AUTHOR: The citation "Meißner et al, } 2016 \text { " has been changed to "Meibner et al., } \\
2016 \text { " to match the author name/date in the reference list. Please check if the change } \\
\text { is fine in this occurrence and modify the subsequent occurrences, if necessary. }\end{array}$ & \\
\hline Q8 & $\begin{array}{l}\text { AUTHOR: Ref. "Loetscher et al., } 2008 \text { " is cited in text but not provided in the reference } \\
\text { list. Please provide details in the list or delete the citation from the text. }\end{array}$ & \\
\hline Q9 & $\begin{array}{l}\text { AUTHOR: The citation "van Belle et al., 2010" has been changed to "van Belle, 2010" } \\
\text { to match the author name/date in the reference list. Please check if the change is fine in } \\
\text { this occurrence and modify the subsequent occurrences, if necessary. }\end{array}$ & \\
\hline Q10 & AUTHOR: Equations have been renumbered. Please check. & \\
\hline Q11 & $\begin{array}{l}\text { AUTHOR: Ref. "Dawes, } 1979 \text { " is cited in text but not provided in the reference list. } \\
\text { Please provide details in the list or delete the citation from the text. }\end{array}$ & \\
\hline Q12 & $\begin{array}{l}\text { AUTHOR: Ref. "Carlsson et al., } 2005 \text { " is cited in text but not provided in the reference } \\
\text { list. Please provide details in the list or delete the citation from the text. }\end{array}$ & \\
\hline Q13 & $\begin{array}{l}\text { AUTHOR: Ref. "Jacquemet et al., 2013" is cited in text but not provided in the } \\
\text { reference list. Please provide details in the list or delete the citation from the text. }\end{array}$ & \\
\hline Q14 & $\begin{array}{l}\text { AUTHOR: Ref. "Özdemir et al., } 2009 \text { " is cited in text but not provided in the reference } \\
\text { list. Please provide details in the list or delete the citation from the text. }\end{array}$ & \\
\hline Q15 & $\begin{array}{l}\text { AUTHOR: Ref. "Borjesson \& Fosgerau, } 2015 \text { " is cited in text but not provided in the } \\
\text { reference list. Please provide details in the list or delete the citation from the text. }\end{array}$ & \\
\hline
\end{tabular}




\begin{tabular}{|c|c|c|}
\hline Query No. & Query & Remark \\
\hline Q16 & $\begin{array}{l}\text { AUTHOR: Ref. "Coast et al., 2012" is cited in text but not provided in the reference list. } \\
\text { Please provide details in the list or delete the citation from the text. }\end{array}$ & \\
\hline Q17 & $\begin{array}{l}\text { AUTHOR: Ref. "Hensher \& Truong, 1985" is cited in text but not provided in the } \\
\text { reference list. Please provide details in the list or delete the citation from the text. }\end{array}$ & \\
\hline Q18 & $\begin{array}{l}\text { AUTHOR: Ref. "Armel et al. (2008)" is cited in text but not provided in the reference } \\
\text { list. Please provide details in the list or delete the citation from the text. }\end{array}$ & \\
\hline Q19 & $\begin{array}{l}\text { AUTHOR: Ref. "Böckenholt \& Hynan, 1994" is cited in text but not provided in the } \\
\text { reference list. Please provide details in the list or delete the citation from the text. }\end{array}$ & \\
\hline Q20 & $\begin{array}{l}\text { AUTHOR: Ref. "Boeri et al., 2013" is cited in text but not provided in the reference list. } \\
\text { Please provide details in the list or delete the citation from the text. }\end{array}$ & \\
\hline Q21 & $\begin{array}{l}\text { AUTHOR: Ref. "Chorus et al., } 2008 \text { " is cited in text but not provided in the reference } \\
\text { list. Please provide details in the list or delete the citation from the text. }\end{array}$ & \\
\hline Q22 & $\begin{array}{l}\text { AUTHOR: Ref. "Chorus, } 2010 \text { " is cited in text but not provided in the reference list. } \\
\text { Please provide details in the list or delete the citation from the text. }\end{array}$ & \\
\hline Q23 & $\begin{array}{l}\text { AUTHOR: Ref. "Chorus, } 2012 \text { " is cited in text but not provided in the reference list. } \\
\text { Please provide details in the list or delete the citation from the text. }\end{array}$ & \\
\hline Q24 & $\begin{array}{l}\text { AUTHOR: Ref. "de Bekker-Grob \& Chorus, } 2013 \text { " is cited in text but not provided in } \\
\text { the reference list. Please provide details in the list or delete the citation from the text. }\end{array}$ & \\
\hline Q25 & AUTHOR: Please define LR if it is an acronym or an abbreviation. & \\
\hline Q26 & $\begin{array}{l}\text { AUTHOR: Ref. "Risko \& Kingstone, } 2011 \text { " is cited in text but not provided in the } \\
\text { reference list. Please provide details in the list or delete the citation from the text. }\end{array}$ & \\
\hline Q27 & $\begin{array}{l}\text { AUTHOR: Ref. "Henry, } 2008 \text { " is cited in text but not provided in the reference list. } \\
\text { Please provide details in the list or delete the citation from the text. }\end{array}$ & \\
\hline Q28 & $\begin{array}{l}\text { AUTHOR: Ref. "Peterson \& Merunka, 2014" is cited in text but not provided in the } \\
\text { reference list. Please provide details in the list or delete the citation from the text. }\end{array}$ & \\
\hline
\end{tabular}

Please confirm that the funding sponsor list below was correctly extracted from your article: that it includes all funders and that the text has been matched to the correct FundRef Registry organization names. If a name was not found in the FundRef registry, it may not be the canonical name form, it may be a program name rather than an organization name, or it may be an organization not yet included in FundRef Registry. If you know of another name form or a parent organization name for a "not found" item on this list below, please share that information.

\begin{tabular}{|l|l|}
\hline FundRef Name & FundRef Organization Name \\
\hline University of Aberdeen & University of Aberdeen \\
\hline
\end{tabular}




\title{
The eyes have it: Using eye tracking to inform information processing strategies in multi-attributes choices
}

\author{
Mandy Ryan ${ }^{1}$ (I) | Nicolas Krucien ${ }^{1}$ (D) | Frouke Hermens ${ }^{2}$
}

\author{
${ }^{1}$ Health Economics Research Unit, \\ Institute of Applied Health Sciences,, \\ University of Aberdeen, Aberdeen, UK \\ ${ }^{2}$ School of Psychology, University of \\ Lincoln, Lincoln, UK

\section{Correspondence} \\ Mandy Ryan, Health Economics Research \\ Unit, Institute of Applied Health Sciences, \\ University of Aberdeen, Aberdeen AB25 \\ 2QN, UK. \\ Email: m.ryan@abdn.ac.uk \\ Funding information \\ University of Aberdeen
}

\begin{abstract}
Although choice experiments (CEs) are widely applied in economics to study choice behaviour, understanding of how individuals process attribute information remains limited. We show how eye-tracking methods can provide insight into how decisions are made. Participants completed a CE, while their eye movements were recorded. Results show that although the information presented guided participants' decisions, there were also several processing biases at work. Evidence was found of (a) top-to-bottom, (b) left-to-right, and (c) first-to-last order biases. Experimental factors-whether attributes are defined as "best" or "worst," choice task complexity, and attribute ordering-also influence information processing. How individuals visually process attribute information was shown to be related to their choices. Implications for the design and analysis of CEs and future research are discussed.
\end{abstract}

\section{KEYWORDS}

choice experiments, choices, eye tracking, information processing

\section{1 | INTRODUCTION}

Recent years have seen an increase in the use of choice experiments (CEs) to value non-marketed commodities (Clark, Determann, Petrou, Moro, \& de Bekker-Grob, 2014; de Bekker-Grob, Ryan, \& Gerard, 2012). Modelling CE responses typically rests on the assumption of utility maximisation (Manski, 1977). However, it is well documented in the decision-making literature that humans deviate from such choice behaviour. Decision-making has been shown to be affected by factors such as number of alternatives, number of attributes, time pressure, and similarity between alternatives, as well as the decision environment and person characteristics (Day et al., 2012; Day \& Pinto Prades, 2010; DeShazo \& Fermo, 2002; Gigerenzer \& Todd, 2001). For example, studies asking participants to verbally express their reasoning processes while making decisions demonstrate that individuals behave as "cognitive misers," adapting effort invested in making a decision to context and resources (Payne, Bettman, \& Johnson, 1993; Shugan, 1980).

Methods to investigate how participants make multi-attribute choices in applied economics are limited. Early research tested for lexicographic preferences (e.g., do respondents always choose the cheapest option?; McIntosh \& Ryan, 2002; Rosenberger, Peterson, Clarke, \& Brown, 2003; Saelensminde, 2006). However, lexicographic preference structures may be consistent with trading, indicating strong preferences rather than violation of the continuity axiom. Research then tried a range of other approaches. For example, Ryan et al. (2009) attempted to probe into underlying decision processes by using "think aloud" methods where participants are asked to vocalise their ongoing decision processes. While finding evidence that "irrational" responses can be rationalised, respondents struggled to think aloud. Another strategy involves determining what makes people ignore information (attribute non-attendance [ANA]), either by asking participants to state which attributes they consider when making their choices (Hole, Kolstad, \& Gyrd-Hansen, 2013; Scarpa, Zanoli, Bruschi, \& Q6 
Naspetti, 2013), or by inferring ANA from their choices (Campbell, Hensher, \& Scarpa, 2011; Hole, 2011; McNair, Hensher, \& Bennett, 2012). However, these two approaches suffer from limitations. Although the stated ANA approach is limited by participants' ability to recall how they reached their decisions (or to critically reflect on how they make their decisions), inferred ANA relies on questionable statistical considerations and provides no understanding of why an attribute is ignored (Hensher, Collins, \& Greene, 2013; Hess, Stathopoulos, Campbell, O'Neill, \& Caussade, 2013).

Recently, it has been suggested that eye tracking may provide a powerful tool for better understanding economic behaviour (Lahey \& Oxley, 2016). A limited but growing number of studies have explored the role of visual attention in economic decision-making (Caplin \& Dean, 2008; Knoepfle, Wang, \& Camerer, 2009; Reutskaja, Nagel, Camerer, \& Rangel, 2011; Wang, Spezio, \& Camerer, 2010). In the CE literature, a small number of studies have used eye tracking to improve the modelling of responses, with a focus on ANA (Balcombe, Fraser, \& McSorley, 2015; Krucien, Ryan, \& Hermens, 2017; Meibner, Musalem, \& Huber, 2016; Spinks \& Mortimer, 2015; Uggeldahl, Jacobsen, Lundhede, \& Olsen, 2016; Van Loo et al., 2015). Our novel work extends this literature, exploring how eye tracking can be used to better Q7 understand how respondents interact with the choice tasks and process multi-attribute information in CEs.

Section 2 describes the design of the experiment, whereas Sections 3 and 4 describe how we link eye movements to choice processes, using fixation times (FTs; the total time spent on a piece of information; Section 3) and fixation transitions (how often the eye shifts from one piece of information to another; Section 4). Section 5 investigates the link between eye movements and choice behaviour. Across all analyses, we consistently find that information processing is subject to biases (in the order in which information is processed) and experimental factors (whether attributes defined as best or worse, difficulty of task, and order of attributes). We also demonstrate that choices can be better modelled when eye-tracking data are incorporated, meaning that eye movement information explains people's choices beyond what information is presented to the participants. The results have important implications for the design and analysis of CEs, which will be discussed. Section 6 discusses limitations of our study, identifying important areas for future research. Section 7 offers concluding comments.

\section{I DESIGN OF THE EXPERIMENT}

\section{1 | Choice experiment}

Participants' choices were recorded for an existing CE on preferences for health and lifestyle programmes to reduce obesity (Ryan et al., 2015). Each programme was described by seven attributes (Table 1). Participants were presented with 14 T1 choice tasks: two warm-up (non-experiment) tasks (\#1 and \#2) and 10 experimental tasks intermixed with a monotonicity and stability check. The warm-up tasks, used to familiarise participants with the format of the choice tasks, were dropped for the eye-tracking analyses. Participants were asked to select their preferred option among two generic health and lifestyle programmes (i.e., Programme A vs. B) and an opt-out ("Current situation") option (Figure 1). The order of the F1 tasks was randomised across participants. Choice tasks were presented on a computer screen. No time limit was imposed.

\section{2 | Experimental manipulation}

Participants were allocated to one of two experimental conditions. In the initial experiment (Experiment $1, N=28$ ), attributes were presented (from top to bottom) in the following order: PROGRAMME, WEIGHT, GOAL, DIABETES, HBP, TIME, and COST. In the second experiment (Experiment 2, $N=30$ ), the order of the attributes was reversed (i. e., COST; TIME; ...; WEIGHT; PROGRAMME), and the location of the choices was switched (Left $\leftrightarrow$ Right). The experiments were otherwise identical.

\section{3 | Eye tracking}

The CE was completed in a dedicated eye-tracking laboratory, and eye movements were recorded using an eye-tracker (EyeLink 1000, SR Research). The eye-tracker was calibrated for each participant using the system's default nine-point procedure. To avoid large head movements, we used a combined head-and-chin rest. The data were divided into fixations (i.e., periods where the eyes remain relatively still) and saccades (i.e., fast eyes' movements during which information processing is suppressed). In line with the eye movement literature, we assume that information extraction only took place during the fixations and that a minimum of $50 \mathrm{~ms}$ was needed for meaningful extraction of information (Tatler, 
TABLE 1 Attributes and levels used to define the health and lifestyle programmes

\begin{tabular}{|c|c|c|c|c|c|c|}
\hline $\begin{array}{c}\text { Comprehensiveness } \\
\text { [PROGRAMME] }\end{array}$ & $\begin{array}{l}\text { Partial (healthy eating } \\
\text { OR physical activity, } \\
\text { with/without support } \\
\text { for management of } \\
\text { weight changes) }\end{array}$ & - & - & $\begin{array}{l}\text { Full (healthy eating AND physical activity, } \\
\text { with/without support for management of } \\
\text { weight changes) }\end{array}$ & $\begin{array}{l}\text { Dummy } \\
\text { (ref: } \\
\text { partial) }\end{array}$ & $\geq 0$ \\
\hline $\begin{array}{l}\text { Weight reduction } \\
\text { [WEIGHT] }\end{array}$ & 0 stone & 0.5 stone & 1 stone & 1.5 stones & Continuous & $\geq 0$ \\
\hline $\begin{array}{l}\text { Reduction in risk } \\
\text { of diabetes } \\
\text { [DIABETES] }\end{array}$ & $0 \%$ & Up to $20 \%$ & $20-40 \%$ & $40-60 \%$ & $\begin{array}{l}\text { Continuous } \\
\qquad(0 ; 20 ; 40 ; \\
60)\end{array}$ & $\geq 0$ \\
\hline $\begin{array}{l}\text { Time per day } \\
\text { [TIME] }\end{array}$ & $120 \mathrm{~min}$ & $90 \mathrm{~min}$ & $60 \mathrm{~min}$ & $30 \mathrm{~min}$ & Continuous & $\leq 0$ \\
\hline $\begin{array}{l}\text { Cost per week } \\
\text { [COST] }\end{array}$ & $£ 20$ & $£ 10$ & $£ 5$ & $£ 1$ & Continuous & $\leq 0$ \\
\hline
\end{tabular}

${ }^{a}$ Attributes are listed by order of appearance in the choice options (i.e., PROGRAMME was located at the top of the options).

${ }^{b}$ WORST/INTERMEDIATE/BEST indicate whether the attribute level was set at its worst/intermediate/best theoretical value (given expected preferences). ${ }^{\mathrm{c}} \mathrm{CODING}$ indicates how the attributes were included in the modelling of participants' choices.

${ }^{\mathrm{d}}$ EXPECTED EFFECT refers to the average preferences for the attribute.

FIGURE 1 Illustration of the choice tasks and regions of interest mapping. Dash squares indicate the regions of interest and were not showed to the subjects during the experiment [Colour figure can be viewed at wileyonlinelibrary.com]

Baddeley, \& Vincent, 2006). Fixations were analysed in terms of where they were directed to with respect to 24 regions of interest (ROI; Figure 1).

The initial dataset included 37,784 fixations, recorded from 58 participants responding to 12 choices. After excluding fixations of less than $50 \mathrm{~ms}, 36,862$ fixations remained: fixations on the column labels (4.6\%); fixations on the multi-attribute content of the two options (84.7\%); fixations on the descriptive column (7.6\%); and fixations on blank space (3.1\%). We further excluded fixations on column labels and blank space, resulting in 34,023 observations for analysis. 


\section{4 | Participants}

The 58 participants were students or former students from the University of Aberdeen (United Kingdom) recruited using online advertisement on a first come, first served basis. They took part in return for course credit or participated without reimbursement. The first 28 participants were allocated to Experiment 1 and the following 30 participants to Experiment 2. The study was approved by the local ethics committee.

The two samples did not differ in terms of socio-demographic characteristics. Male participants made up $52 \%$ of the sample (13/25) in Experiment 1 and 31\% (9/29) in Experiment $2\left(\chi^{2}=1.653 ; p=.198\right)$. Information about height and weights was used to compute the body mass index-72\% (18/25) of participants had a normal body mass index in Experiment 1 versus $69 \%$ in Experiment $2\left(20 / 29 ; \chi^{2}<0.001 ; p>.999\right)$. The two samples were also similar in terms of age, with a mean age of $20.83(S D=1.73)$ and $20.48(S D=2.33)$ for Experiments 1 and 2 , respectively $(t=0.614 ; p=.542)$.

\section{3 | DETERMINANTS OF FIXATION TIMES}

A range of measures has been developed to analyse visual attention (e.g., FT, fixation frequency/count, and pupil dilation; Duchowski, 2007; Holmqvist, 2011). We focus on the total FT on each ROI, previously used as a measure of information interest and difficulty (Rayner, 1998). To avoid strong effects of long fixations on a piece of evidence, and to reduce the skew of the distribution, we used the natural logarithm of FT, which was computed for each ROI (see Figure 1) at the participant by task level. Using mixed effects linear models, we investigate the extent to which $\ln (\mathrm{FT})$ is influenced by the following CE factors:

- The LEFT parameter $\left(\beta_{1}\right)$ captures the systematic effect of an ROI belonging to the left alternative compared to the right. Such an effect would be consistent with a "left-to-right" reading bias where participants pay more attention to information presented on the left (Durgin, Doyle, \& Egan, 2008; Guo, Meints, Hall, Hall, \& Mills, 2009; Rayner, 1978, 1998). Leftward biases are also found in other tasks, including digit comparison (Loetscher et al., 2008), picture Q8 scanning and line bisection (Foulsham, Cheng, Tracy, Henrich, \& Kingstone, 2010), visual search (Durgin et al., 2008), reading Chinese characters, and face perception (Butler et al., 2005; Everdell, Marsh, Yurick, Munhall, \& Par, 2007; van Belle, 2010). We expect participants to spend more time looking at the left options (H1: $\left.\beta_{1}>0\right)$.

- Two POSITION parameters capture the effects of the attributes position within the choice tasks. $\beta_{2}$ and $\beta_{3}$ measure respectively the effect of being top located (1st or 2 nd position) and bottom located (6th or 7th position) versus being middle located (i.e., 3rd, 4th, or 5th position). This would also be consistent with typical reading patterns and has been found in other domains such as visual search (Durgin et al., 2008). Within the CE literature, there is evidence of ordering effects on estimated preferences (Kjær, Bech, Gyrd-Hansen, \& Hart-Hansen, 2006; Scott \& Vick, 1999). Thus, first and last consulted pieces of information may receive a visual attention bonus-malus. We expect FTs to differ for the top (H2[a]: $\left.\beta_{2} \neq 0\right)$ and bottom located attributes $\left(\mathrm{H} 2[\mathrm{~b}]: \beta_{3} \neq 0\right)$.

- The two LEVEL parameters $\left(\beta_{4}\right.$ and $\left.\beta_{5}\right)$ capture the effects of attributes' value, either BEST or WORST, on visual attention. An attribute is classified as BEST when it is set at its most desirable level (e.g., lowest price) and WORST when set at least desirable level (e.g., highest price; Table 1). We expect extreme information, either BEST or WORST, to be more psychologically salient (compared to INTERMEDIATE), thus attracting more attention (H3[a]: $\beta_{4}>0 ; \mathrm{H} 3[\mathrm{~b}]: \beta_{5}>0$ ). In line with loss aversion, participants are expected to be more sensitive to negatively framed information (Kahneman, Knetsch, \& Thaler, 1991). We therefore expect participants to be more attentive to WORST than BEST information $\left(\mathrm{H} 3[\mathrm{c}]: \beta_{4}<\beta_{5}\right)$. Our classification of attributes' levels as BEST, INTERMEDIATE, or WORST is based on results from Ryan et al. (2015), which administered the same CE questionnaire to a representative sample of the U.K. population.

- Two TRIAL parameters $\left(\beta_{6}\right.$ and $\left.\beta_{7}\right)$ capture the effect of task sequence (i.e., position of the choice tasks within the questionnaire). Previous studies have reported the effects of task ordering on the consistency of respondents' choices (Bateman, Diane, George Hutchinson, \& Matthews, 2008; Day et al., 2012; Mantonakis, Rodero, Lesschaeve, \& Hastie, 2009), suggesting learning and fatigue effects. We assume that as respondents progress through the choice tasks, they become more efficient in their information search, reducing FTs on the ROI (H4[a]: $\left.\beta_{6}<0\right)$. However, this effect is expected to become marginally smaller over the sequence of tasks $\left(\mathrm{H} 4[\mathrm{~b}]: \beta_{7}>0\right)$.

- The DIFFICULTY parameter $\left(\beta_{8}\right)$ captures the impact of choice difficulty. Shugan (1980) argues that difficulty is inversely related to perceptual similarity-highly different options are more difficult. As alternatives become less similar, the variance in the values on the attributes across alternatives increases. This can be captured by the dispersion of the standard deviation (DSD) among attribute levels across alternatives (DeShazo \& Fermo, 
TABLE 2 Mixed effects regression of $\ln ($ fixation times)

\begin{tabular}{|c|c|c|c|}
\hline & MLE & $S E$ & $p$ \\
\hline Constant & 6.204 & 0.063 & $<.001$ \\
\hline POSITION (top) & 0.259 & 0.018 & $<.001$ \\
\hline POSITION (bottom) & -0.170 & 0.019 & $<.001$ \\
\hline LEVEL (best) & 0.090 & 0.021 & $<.001$ \\
\hline TRIAL & -0.039 & 0.009 & $<.001$ \\
\hline TRIAL $\times$ TRIAL & 0.002 & 0.001 & $<.001$ \\
\hline DIFFICULTY (DSD) & 0.336 & 0.091 & $<.001$ \\
\hline EXPERIMENT & 0.182 & 0.071 & .010 \\
\hline Individual errors & 0.264 & - & - \\
\hline Observation errors & 0.680 & - & - \\
\hline Log-likelihood & $8,816.8$ & & \\
\hline
\end{tabular}

DSD $=$ dispersion of standard deviation; MLE $=$ maximum likelihood estimate.

2002). ${ }^{1}$ A priori, it is hypothesised that as DSD increases, choice sets become less similar, and participants spend more time processing the multi-attribute information (H5: $\left.\beta_{8}>0\right)$.

- The EXPERIMENT parameter $\left(\beta_{9}\right)$ captures the effect of reversing the order of attributes and two choice options (over and above LEFT and POSITION). Using brain imaging, Karmarkar, Shiv, and Knutson (2015) found that different orderings of product features was associated with different decision rules/objectives; that is, when the product price was presented first, participants were more likely to focus on whether the product was worth its price. We expect FTs to significantly differ across experiments $\left(\mathrm{H} 6: \beta_{9} \neq 0\right)$.

We thus estimate:

$$
\begin{aligned}
& \ln \left(\mathrm{FT}_{\mathrm{ntr}}\right)=\beta_{0}+\beta_{1} \text { LEFT }_{\mathrm{ntr}}+\beta_{2: 3} \text { POSITION }_{\mathrm{ntr}}+\beta_{4: 5} \text { LEVEL }_{\mathrm{ntr}}+\beta_{6: 7} \text { TRIAL }_{\mathrm{ntr}}+ \\
& \beta_{8} \text { DIFFICULTY }_{\mathrm{ntr}}+\beta_{9} \text { EXPERIMENT }_{\mathrm{ntr}}+\omega_{\mathrm{n}}+\varepsilon_{\mathrm{ntr}},
\end{aligned}
$$

where $\left(\mathrm{FT}_{\mathrm{ntr}}\right)$ indicates the FT on ROI (r) by respondent (n) at task (t). The errors ( $\omega$ and $\varepsilon$ ) are assumed to be multivariate normally distributed and uncorrelated. Given that we use $\ln (\mathrm{FT})$ as the dependent variable, estimates can be interpreted as the $\%$ change in the FT by taking their exponent, that is, $\exp (\beta)$.

Results are presented in Table 2. Attributes of the left option were fixated on average $+16 \%$ longer than those of the T2 right option, suggesting a left-to-right bias in visual attention, in agreement with studies in other domains (see above). Part of this bias may be the result of the reading direction (left-to-right) in our participants, and an interesting future direction would therefore be to study whether this bias is reversed when using a language with right-to-left reading direction (e.g., Arabic, Farsi, Hebrew, and Urdu). This visual bias may explain why CEs often find a significant constant term in generic choices. This finding suggests that randomising the order of the alternatives within the choice tasks may improve the quality of CE data.

The first two attributes were looked at longer than the middle positioned attributes $(+30 \%)$, whereas the bottom located attributes were looked at less $(-16 \%)$. These effects indicate a top-to-bottom visual bias when processing vertically presented (multi-attribute) information. Our finding suggests that observed top-to-bottom biases in CE may have their origin in stronger visual attention to attributes shown at the top. This suggests that it is important to randomise the order of attributes. We suggest that this randomization is best done at the participant level (i.e., the order

\footnotetext{
${ }^{1}$ The entropy measure is often used to capture task difficulty in CEs, describing the similarity of alternatives. Entropy is typically constructed using participant responses, creating an endogeneity problem; that is, entropy is a function of the probability of selecting each of the available alternatives and thus may be a consequence of fixation time (rather than vice versa). We thank the reviewer for this comment and thus use the DSD measure (which does not rely on respondent preferences). Appendix S1 compares the results using entropy and DSD measures; the main results remain unchanged.
} 
of the attributes would differ across participants but remains the same for all tasks faced by the same participant), because otherwise, participants have to adopt to a new order of attributes on every single choice.

Negatively (WORST) framed attributes were less looked at (-4\%), whereas positively (BEST) framed attributes were associated with longer FTs (+9\%). The finding suggests that respondents give relatively more consideration to attributes with positive outcomes, consistent with Dawes' rule (Dawes, 1979), where alternatives with the highest number of Q11 positive aspects are chosen more often. Note that this finding is inconsistent with loss aversion, which predicted that negatively framed attributes would be fixated for longer. A possible reason for failing to find evidence of loss aversion may be that we dealt with hypothetical (non-consequential) choices, and it would therefore be interesting to determine whether the same result is obtained for actual choices (e.g., people making decisions in a doctor's surgery). Alternatively, future studies could examine whether one of the approaches to mitigate such hypothetical bias (e.g., cheap talk script and oath protocol; Carlsson et al., 2005; Jacquemet et al., 2013; Özdemir et al., 2009) influences the bias towards positively framed attributes that we found here.

Both TRIAL variables had a significant effect on FT. The significant and negative trial number effect indicates that as participants progress through the sequence of tasks, they spend less time looking at the different ROIs (first-to-last bias). The quadratic effect indicates that the marginal change in FT decreases over time. This result suggests that first observed choices could be contaminated by participants adjusting to the task, and respondents may change their choice behaviour(s) during the study. Such an interpretation would agree with findings showing significantly longer responses time for the first task (Borjesson \& Fosgerau, 2015). The present results, because we used two warm-up trials, suggest Q15 that longer FTs last beyond the first task. It is therefore important to randomise the order of choices across participants so that in the average data, such effects can be minimised.

The DIFFICULTY (DSD) parameter describes a positive relationship between task difficulty and visual attention. Participants spend more time fixating attributes when facing difficult choice tasks. This result is important for the design of CEs. While on the one hand, one would like to maximise the information gained from each trial by making the choice tasks more challenging, it could, on the other hand, wear out participants. This is in line with suggestions that statistical efficiency (i.e., information gained from each choice) is negatively correlated with the respondents' efficiency (i.e., the ability of participants to make informed decisions; Flynn, Bilger, Malhotra, \& Finkelstein, 2016; Viney, Savage, \& Louviere, 2005). Our study suggests that although increased statistical efficiency could wear participants out, it seems to improve respondents' attention, possibly leading to more informed decisions. The question arises to when this positive benefit on attention breaks down (e.g., after how many trials), which could be an interesting topic for future research.

The EXPERIMENT variable significantly contributed to the prediction of the FTs. This means that the ordering of the attributes influenced FTs beyond the effects of the attributes being left or right, or top or bottom. This suggests that besides considering what attributes to include (e.g., Coast et al., 2012), the design of CEs should also consider in what Q16 order the attributes are presented, particularly when computerised CEs are employed. When randomising is not an option (e.g., for pen-and-paper surveys), a second best solution may be to define "experientially meaningful configurations" (Hensher \& Truong, 1985), which uses an ordering of attributes that is consistent with different steps Q17 in the process involved (e.g., for a medical appointment, the delay to get an appointment, the distance to travel, the waiting time, the length of consultation, and out-of-pocket expense).

\section{4 | DETERMINANTS OF FIXATION TRANSITIONS}

So far, we have only considered how long people look at attributes. This, however, discounts temporal information on the order in which attributes are processed. There are indications that the order of processing is important for decision-making. For example, Armel et al. (2008) showed that first fixated product (option) was more likely to be selected ceteris paribus. Likewise, participants are more likely to choose the option they look at last (Shimojo, Simion, Shimojo, \& Q18 Scheier, 2003). To analyse order effects, we here examine transitions (i.e., eye movements between ROI) as a function of time in the trials (percentage of the trials). We define four transition categories: option-wise (vertical reading), where participants move their eyes across ROI belonging to the same option (e.g., TIME [A] $\rightarrow$ COST [A]); attribute-wise (horizontal reading), where participants compare options on an attribute-by-attribute basis (e.g., COST [A] $\rightarrow$ COST [B]); refixations, where participants consecutively fixate on the same ROI (e.g., COST [A] $\rightarrow$ COST [A]); and hybrid, where participants move their eyes across ROI belonging to different options (e.g., TIME [A] $\rightarrow$ COST [B]). If people first form an overall impression of each choice option and then compare these overall impressions, we expect more option-wise transitions. If they compare the attributes of the two choice options directly, we expect more attribute-wise transitions. 


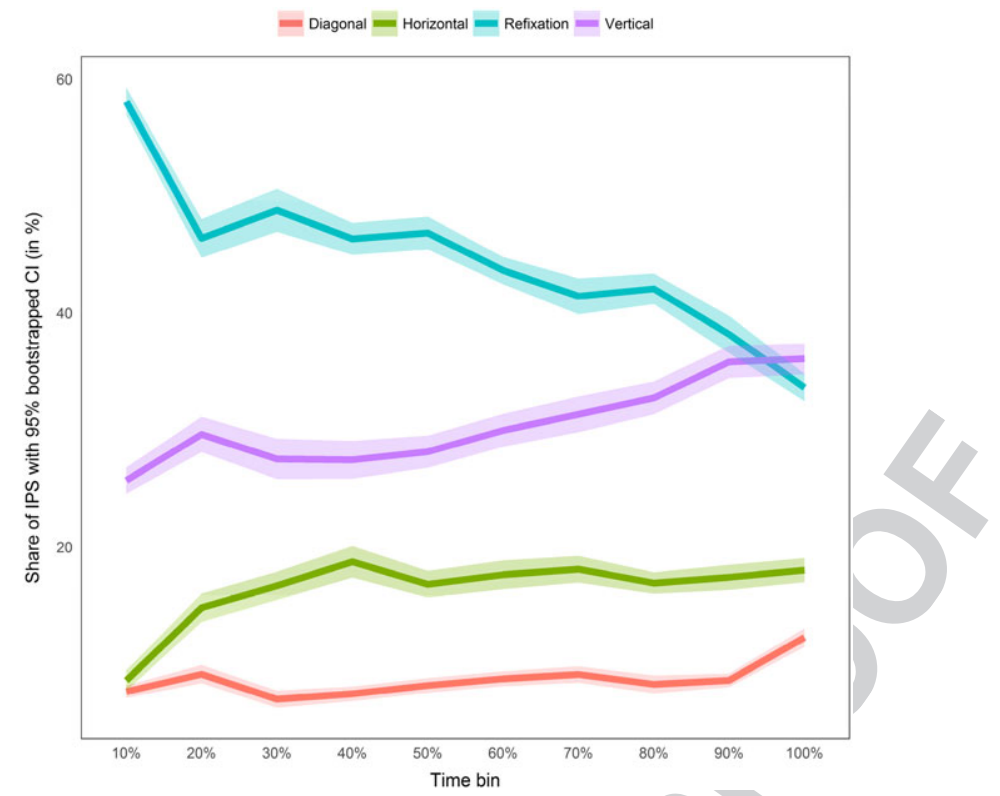

FIGURE 2 Evolution of information processing strategies (IPS) over (fixation) time [Colour figure can be viewed at wileyonlinelibrary. com]

Our dataset initially included 34,023 transitions. Those corresponding to a transition from the descriptive column (i. e., ROI 1 to 8 in Figure 1) were excluded, leaving 29,641 (87.1\%) transitions: 13,548 (45.7\%) refixations; 8,645 (29.2\%) option-wise; 4,898 (16.5\%) attribute-wise; and 2,550 (8.6\%) hybrid. (Detailed information about transitions is provided in Appendix S2.) Figure 2 shows the time course of transitions across choices, clustered into 10 time bins for each trial $\mathbf{F 2}$ (i.e., beginning of the information processing period [0-10\%]; ...; end of information processing period [90-100\%]). Visual information processing mainly consists of refixations and option-wise transitions: Participants initially (i.e., first three time bins) process the multi-attribute information mainly with refixations before exploring the content of each option separately (i.e., option-wise transitions).

We investigate transitions as a function of three task-related variables: TRIAL (Task order); Dispersion of Standard deviation (DSD; Task difficulty); and EXPERIMENT (Experiment 1 or 2). As the dependent measure, we use the search measure (SM) index (Böckenholt \& Hynan, 1994), which measures the degree to which information is processed vertically or horizontally (see Appendix S2 for more details about the SM measure). SM is computed as

$$
\mathrm{SM}=\frac{\sqrt{\mathrm{TR}}\left(\frac{\mathrm{JK}}{\mathrm{TR}}\left(\mathrm{TR}_{J}-\mathrm{TR}_{K}\right)-(K-J)\right)}{\sqrt{J^{2}(K-1)+K^{2}(J-1)}},
$$

where $J$ corresponds to the number of choice options $(J=2), K$ the number of attributes $(K=7)$, TR the total number of transitions, $\mathrm{TR}_{\mathrm{K}}$ the number of attribute-wise transition, and $\mathrm{TR}_{\mathrm{J}}$ the number of option-wise transitions. The $\mathrm{SM}$ measure is zero for random search behaviour, ${ }^{2}$ negative for more attribute-wise (horizontal) transitions, and positive for more option-wise (vertical) transitions. We compute the SM index for each participant (n) and choice task (t). The square root of the absolute value of the SM index for each participant (n) and choice task ( $\mathrm{t}$ ) was then modelled in a mixed effects linear regression model:

$$
\sqrt{\left|\mathrm{SM}_{\mathrm{nt}}\right|}=\beta_{0}+\beta_{1} \text { TRIAL }_{\mathrm{nt}}+\beta_{2} \text { TRIAL }_{\mathrm{nt}}^{2}+\beta_{3} \mathrm{DSD}_{\mathrm{nt}}+\beta_{4} \text { EXPERIMENT }_{\mathrm{nt}}+\omega_{\mathrm{n}}+\varepsilon_{\mathrm{nt}},
$$

where $\omega$ measures between-subjects variance, accounting for panel nature of the data. Modelling the absolute value of $\mathrm{SM}$ index allows investigation into deviations from random information processing (i.e., $\mathrm{SM}=0$ ).

On the basis of the theory by DeShazo and Fermo (2002) that participants to a CE allocate their limited attention in a rationally adaptive manner, we predict that over the course of the experiment, when fatigue sets in, participants' choices

${ }^{2} \mathrm{SM}$ does not evaluate the quality of information processing but only how the information is being visually processed. Thus, a "random search" (SM $=0$ ) does not necessarily imply poor decision-making. 
become more random (i.e., the absolute value of SM will reduce). For task difficulty, fixation patterns could become more structured (i.e., the absolute value of SM increases). The order of the attributes and choice options (EXPERIMENT) may also influence the absolute value of SM, but the direction of the effect is more difficult to predict.

For the entire dataset, a negative value for SM is obtained in 621 (89.2\%) cases, indicating attribute-wise (horizontal) information processing. Regression results, shown in Table 3, confirm our predictions. The direction of eye movements T3 becomes more random over the course of the experiment (negative effect of TRIAL) but more structured for more difficult choices (positive effect of DSD) and more structured when COST is presented at the top (positive effect of EXPERIMENT).

\section{5 | VISUAL ATtENTION AND CHOICE BEHAVIOUR}

Finally, we examine how transitions (as measured by the SM variable) are linked to choice. Previous studies have shown that ANA (or more generally attributes attention) is linked to eye movements during the choice (Balcombe et al., 2015; Krucien et al., 2017; Spinks \& Mortimer, 2015). By examining how transitions are linked to choices, we can test the prediction of random regret minimisation (RRM; Boeri et al., 2013; Chorus et al., 2008; Chorus, 2010; Chorus, 2012; de Bekker-Grob \& Chorus, 2013) that multi-attribute information is processed on an attribute basis. In comparison, random utility maximisation (RUM) does not impose a particular type of information processing. Thus,

RUM

$$
\begin{gathered}
\text { UTILITY }_{\mathrm{ntA}}=\left(\Sigma_{\mathrm{k}} \beta_{\mathrm{k}} \mathrm{X}_{\mathrm{ntAk}}\right)+\varepsilon_{\mathrm{ntA}}, \\
\text { UTILITY }_{\mathrm{ntB}}=\left(\Sigma_{\mathrm{k}} \beta_{\mathrm{k}} \mathrm{X}_{\mathrm{ntBk}}\right)+\varepsilon_{\mathrm{ntB}}, \\
\mathrm{P}\left(\mathrm{Y}_{\mathrm{nt}}=\mathrm{A}\right)=\mathrm{P}\left(\mathrm{U}_{\mathrm{ntA}}>\mathrm{U}_{\mathrm{ntB}}\right)=\mathrm{P}\left(\mathrm{V}_{\mathrm{ntA}}-\mathrm{V}_{\mathrm{ntB}}>\varepsilon_{\mathrm{ntB}}-\varepsilon_{\mathrm{ntA}}\right), \\
\text { DIFFERENCE }_{\mathrm{UTILITY}_{\mathrm{nt}}}=\left(\Sigma_{\mathrm{k}} \beta_{\mathrm{k}}\left(\mathrm{X}_{\mathrm{ntAk}}-\mathrm{X}_{\mathrm{ntBk}}\right)\right)+\varepsilon_{\mathrm{nt}},
\end{gathered}
$$

RRM

$$
\begin{aligned}
& \operatorname{REGRET}_{\mathrm{ntA}}=\left[\Sigma_{\mathrm{k}} \ln \left(1+\exp \left(\beta_{\mathrm{k}}\left(\mathrm{X}_{\mathrm{ntB}(\mathrm{k})}-\mathrm{X}_{\mathrm{ntA}(\mathrm{k})}\right)\right)\right)\right]^{\alpha}+\varepsilon_{\mathrm{ntA}}, \\
& \operatorname{REGRET}_{\mathrm{ntB}}=\left[\Sigma_{\mathrm{k}} \ln \left(1+\exp \left(\beta_{\mathrm{k}}\left(\mathrm{X}_{\mathrm{ntA}(\mathrm{k})}-\mathrm{X}_{\mathrm{ntB}(\mathrm{k})}\right)\right)\right)\right]^{\alpha}+\varepsilon_{\mathrm{ntB}},
\end{aligned}
$$

\begin{tabular}{|c|c|c|c|}
\hline & MLE & $S E$ & $p$ \\
\hline Constant & 1.501 & 0.089 & $<.001$ \\
\hline TRIAL $\times$ TRIAL & 0.001 & 0.001 & .652 \\
\hline DIFFICULTY (DSD) & 0.020 & 0.165 & .905 \\
\hline EXPERIMENT & 0.381 & 0.093 & $<.001$ \\
\hline Observation error & 0.356 & - & - \\
\hline \multicolumn{4}{|l|}{ 2. Model statistics } \\
\hline \# Observations & 696 & & \\
\hline \# Parameters & 6 & & \\
\hline Log-likelihood & 352.3 & & \\
\hline
\end{tabular}

where $\mathrm{n}$ denotes the respondents, $\mathrm{t}$ the choice tasks, $\mathrm{k}$ the attributes, and $\mathrm{X}$ the value of the attributes. The $(\beta)$ parameters represent preferences for attributes. The $(\varepsilon)$ errors are assumed to be independently and identically distributed as type I extreme value leading to the multinomial logit model (McFadden, 1974; Train, 2009).

TABLE 3 Mixed effects regression of SM index

$\mathrm{SM}=$ search measure; MLE = maximum likelihood estimate. 
TABLE 4 MNL modelling of discrete choices with RUM and RRM approaches

\begin{tabular}{|c|c|c|c|c|c|c|}
\hline & \multicolumn{3}{|l|}{ RUM } & \multicolumn{3}{|l|}{ RRM } \\
\hline \multicolumn{7}{|c|}{ 1. Model parameters } \\
\hline GOAL & 0.885 & 0.183 & $<.001$ & 0.891 & 0.181 & $<.001$ \\
\hline WEIGHT & 0.490 & 0.155 & .002 & 0.526 & 0.156 & $<.001$ \\
\hline TIME & -0.015 & 0.002 & $<.001$ & -0.015 & 0.002 & $<.001$ \\
\hline COST & -0.029 & 0.011 & .009 & -0.028 & 0.011 & .011 \\
\hline $\mathrm{SM}^{+}(\alpha 1)$ & - & - & - & 0.360 & 0.331 & .277 \\
\hline $\mathrm{SM}^{+}(\alpha 2)$ & - & - & - & -0.115 & 0.190 & .547 \\
\hline $\mathrm{SM}^{-}(\alpha 3)$ & - & - & - & -0.135 & 0.069 & .049 \\
\hline Log-likelihood & 346.1 & & & 343.7 & & \\
\hline
\end{tabular}

$\mathrm{MLE}=$ maximum likelihood estimate $\mathrm{MNL}=$ multinomial logit $\mathrm{RRM}=$ random regret minimisation $; \mathrm{RUM}=$ random utility maximisation.

Because very few opt-out responses were given, ${ }^{3}$ we only consider responses for either choice A or B, meaning that the REGRET function (Equations 8 and 9) collapses into the standard UTILITY function (Equations 4 and 5) when $\alpha=1$. We investigate the impact of visual attention on participants' choices by specifying the $\alpha$ parameter as a function of the SM index:

$$
\alpha=\exp \left(\alpha_{1} \mathrm{SM}^{+}{ }_{\mathrm{nt}}+\alpha_{2} \mathrm{SM}^{+2}{ }_{\mathrm{nt}}+\alpha_{3} \mathrm{SM}^{-}{ }_{\mathrm{nt}}+\alpha_{4} \mathrm{SM}^{-2}{ }_{\mathrm{nt}}\right),
$$

where $\mathrm{SM}^{+}$and $\mathrm{SM}^{-}$correspond to the positive and negative portions of the $\mathrm{SM}$ index, respectively. A negative $\mathrm{SM}$ (SM ${ }^{-}$) indicates a tendency to process information on an attribute basis, whereas a positive SM (SM+) corresponds to a vertical information processing. We expect $\alpha_{1}$ to be non-significant $\left(\mathrm{H} 1: \alpha_{1}=0\right)$, because vertical information processing makes RUM and RRM more alike $\left(\alpha_{1} \approx 0 \rightarrow \alpha \approx 1\right)$. We expect $\alpha_{3}$ to be significant $\left(\mathrm{H} 2: \alpha_{3} \neq 0\right)$ as attribute-wise information processing would be better captured by RRM than RUM.

The results are presented in Table 4. The RRM model provides a better account of participants' choices, as indicated T4 by the lower log-likelihood $(\mathrm{LL})$ value $\left(\mathrm{LL}_{\mathrm{RRM}}=343.7 \mathrm{vs}\right.$. $\left.\mathrm{LL}_{\mathrm{RUM}}=346.1\right)$. However, this improvement does not reach significance at $5 \%$ level (LR test: Deviance $=4.88 ; p=.3$ ). As expected, $\mathrm{SM}^{-}$has a significant and negative effect, Q25 indicating that when information processing became more attribute-wise, the RUM and RRM provide a different account of participants' choices.

\section{6 | DISCUSSION}

In the present work, we show that eye tracking can aid the understanding of information processing strategies in multiattribute choice. Our results have important implications for the design and modelling of CEs, thus improving the validity of resulting policy recommendations. We found a range of visual biases that agree with earlier reported choice biases, including a left-to-right, top-to-bottom, and first-to-last. Our work suggests that many of these biases originate in the deployment of visual attention during a CE. Importantly, these biases indicate that CE data can be substantially improved by randomising the order of alternatives, attributes, and choice trials. Although pen-and-paper randomisation may be complicated (although not impossible on a participant by participant basis), an increased reliance on computerised CEs (e.g., presented on a computer tablet or online via a web browser) will facilitate such randomisation. Our analyses also demonstrate effects of task factors, including whether attributes are defined as best or worse, the level

${ }^{3}$ The initial sample included 58 participants who provided 696 observations. The opt-out option was selected in only 48 (6.9\%) cases. For 53 (91.4\%) participants, the share of opt-out choices was below $25 \%$ (i.e., less than three choices). The highest proportion of opt-out choices (i.e., $58.3 \%$ ) was attained by two (3.4\%) participants. After removing opt-out choices, 648 (93.1\%) observations remained. 
of complexity of the choice task, and ordering of attributes. Our data also showed that the RRM model outperformed the RUM model in linking eye movements with respondents' choice behaviour, although the exact link between eye movements and choice behaviour needs to be established in future research.

Because CEs contain words (besides numerical information), this raises the question to what extent factors that influence reading also influence eye movements when completing a CE. For reading, it is known that fixation durations are longer for less frequent (familiar) words, less predictable words, and for words with multiple meanings (Rayner, 1998). The extent to which these factors influence FTs during CEs is unclear. In comparison to normal text, text in CEs is repeated often, which increases the predictability of the words. It is therefore likely that participants do not read all of the words of boxes containing longer text (the resolution of the eye-tracker used may not suffice to answer this question with sufficient confidence). Furthermore, we included two warm-up trials, which is expected to increase predictability further. In all, we therefore do not expect strong effects of word properties on processing a CE. A second possible factor involves reading ability of our participants. Although we did not test explicitly for this, our participant groups were uniform on a broad range of other factors (all current or former students). Moreover, most of the effects tested in our study involved within subjects comparisons (the only exception being the EXPERIMENT factor), which are less likely to be influenced by individual differences.

There are a few possible limitations to our study. First, the act of eye tracking may influence visual attention. This, however, is unlikely to influence the present results. Although studies in social attention suggest that awareness of the recording of eye movements influences the direction of visual attention (Risko \& Kingstone, 2011), these results are for objects that are Q26 socially less acceptable to be gazed at (e.g., a swimsuit calendar on the wall). No eye-tracker bias is found for neutral objects.

Second, and perhaps more notable, our eye-tracker used a chin-and-forehead rest. The use of such equipment is not uncommon in eye-tracking studies, particularly those requiring high spatial accuracy of the recordings (as in studies of reading; Rayner, 1978, 1998). The restriction of head movements, however, may have reduced the frequency of looking away from the text. Examining the effects of head restriction would be an interesting venue for future research, particularly now that mobile eye-tracking technology is becoming more mainstream and more accurate.

Third, our sample, psychology students, was not representative of the U.K. population. The use of a student sample is in line with many studies in consumer research and social psychology (Henry, 2008), mostly because they are easier to recruit Q27 for lab-based studies. There are indications that students may not be representative of the general population, as they tend to have stronger cognitive skills and show more compliant behaviour (Peterson \& Merunka, 2014). Thus, the generalisability of Q28 our findings is limited. However, although choices may differ for a different population, there are no clear reasons to believe that the link between visual attention and choices and visual biases will depend on the population studied. With the development of more portable eye-tracking equipment (e.g., EyeTribe, Eyelink Portable Duo, SMI Red250 Portable, Tobii X2-60, Tobii 2 Glasses, SMI Glasses, and Positive Science eye-tracker), future research should aim to move the work to a broader population-based sample and move from the laboratory into clinical and community settings.

Finally, we note that in our multivariate analysis of FTs, we investigated whether "better" attributes attract more attention (and conversely "worse" attribute less attention). Although for the quantitative attributes (e.g., reduction of risk of hypertension), it is clear what defined "better," we had to base our assumptions regarding best and worst levels on responses to the original CE, generated from the general population. Whether these extend to our student population needs to be addressed in future research.

\section{7 | CONCLUDING REMARKS}

Our study shows how eye tracking provides insight into how respondents complete CEs, suggesting a number of biases and context-related decision strategies. As well as providing guidance to CE practitioners on the design and analysis of CE data, we hope our paper stimulates discussion of the use of eye tracking in applied economic research. As Lahey and Oxley (2016) commented, research with an eye-tracker is limited only by our imagination.

\section{ACKNOWLEDGEMENTS}

The University of Aberdeen and the Chief Scientist Office of the Scottish Government Health and Social Care Directorates fund the Health Economics Research Unit (HERU). We thank all participants who took part in the study and Pavlos Topalidis for invaluable help with data collection. We thank two anonymous referees for their comments and suggestions that helped improve this article. 


\section{ORCID}

Mandy Ryan (D) http://orcid.org/0000-0001-6643-9129

Nicolas Krucien (i) http://orcid.org/0000-0001-9179-6558

\section{REFERENCES}

Balcombe, K., Fraser, I., \& McSorley, E. (2015). Visual attention and attribute attendance in multi-attribute choice experiments: DISCRETECHOICE EXPERIMENTS AND EYE-TRACKING. Journal of Applied Econometrics, 30(3), 447-467. https://doi.org/10.1002/jae.2383.

Bateman, I. J., Diane, B., George Hutchinson, W., \& Matthews, D. I. (2008). Learning design contingent valuation (LDCV): NOAA guidelines, preference learning and coherent arbitrariness. Journal of Environmental Economics and Management, 55(2), 127-141. https://doi.org/ 10.1016/j.jeem.2007.08.003.

Butler, S., Gilchrist, I. D., Burt, D. M., Perrett, D. I., Jones, E., \& Harvey, M. (2005). Are the perceptual biases found in chimeric face processing reflected in eye-movement patterns? Neuropsychologia, 43(1), 52-59. https://doi.org/10.1016/j.neuropsychologia.2004.06.005.

Campbell, D., Hensher, D. A., \& Scarpa, R. (2011). Non-attendance to attributes in environmental choice analysis: A latent class specification. Journal of Environmental Planning and Management, 54(8), 1061-1076. https://doi.org/10.1080/09640568.2010.549367.

Caplin, A., \& Dean, M. (2008). Economic insights from 'neuroeconomic' data. American Economic Review, 98(2), 169-174. https://doi.org/ 10.1257/aer.98.2.169.

Clark, M. D., Determann, D., Petrou, S., Moro, D., \& de Bekker-Grob, E. W. (2014). Discrete choice experiments in health economics: A review of the literature. PharmacoEconomics, 32(9), 883-902. https://doi.org/10.1007/s40273-014-0170-x.

Day, B., Bateman, I. J., Carson, R. T., Dupont, D., Louviere, J. J., Morimoto, S., ... Wang, P. (2012). Ordering effects and choice set awareness in repeat-response stated preference studies. Journal of Environmental Economics and Management, 63(1), 73-91. https://doi.org/10.1016/j. jeem.2011.09.001.

Day, B., \& Pinto Prades, J.-L. (2010). Ordering anomalies in choice experiments. Journal of Environmental Economics and Management, 59(3), 271-285. https://doi.org/10.1016/j.jeem.2010.03.001.

de Bekker-Grob, E. W., Ryan, M., \& Gerard, K. (2012). Discrete choice experiments in health economics: A review of the literature. Health Economics, 21(2), 145-172. https://doi.org/10.1002/hec.1697.

DeShazo, J. R., \& Fermo, G. (2002). Designing choice sets for stated preference methods: The effects of complexity on choice consistency. Journal of Environmental Economics and Management, 44(1), 123-143. https://doi.org/10.1006/jeem.2001.1199.

Duchowski, A. T. (2007). Eye tracking methodology: Theory and practice (2nd ed.). London: Springer.

Durgin, F. H., Doyle, E., \& Egan, L. (2008). Upper-left gaze bias reveals competing search strategies in a reverse Stroop task. Acta Psychologica, 127(2), 428-448. https://doi.org/10.1016/j.actpsy.2007.08.007.

Everdell, I. T., Marsh, H., Yurick, M. D., Munhall, K. G., \& Par, M. (2007). Gaze behaviour in audiovisual speech perception: Asymmetrical distribution of face-directed fixations. Perception, 36(10), 1535-1545. https://doi.org/10.1068/p5852.

Flynn, T. N., Bilger, M., Malhotra, C., \& Finkelstein, E. A. (2016). Are efficient designs used in discrete choice experiments too difficult for some respondents? A case study eliciting preferences for end-of-life care. PharmacoEconomics, 34(3), 273-284. https://doi.org/10.1007/ s40273-015-0338-z.

Foulsham, T., Cheng, J. T., Tracy, J. L., Henrich, J., \& Kingstone, A. (2010). Gaze allocation in a dynamic situation: Effects of social status and speaking. Cognition, 117(3), 319-331. https://doi.org/10.1016/j.cognition.2010.09.003.

Gigerenzer, G., \& Todd, P. M. (2001). Simple heuristics that make us smart. 1. issued as an Oxford Univ. Press paperback. Evolution and Cognition. Oxford: Oxford Univ. Press.

Guo, K., Meints, K., Hall, C., Hall, S., \& Mills, D. (2009). Left gaze bias in humans, rhesus monkeys and domestic dogs. Animal Cognition, 12(3), 409-418. https://doi.org/10.1007/s10071-008-0199-3.

Hensher, D. A., Collins, A. T., \& Greene, W. H. (2013). Accounting for attribute non-attendance and common-metric aggregation in a probabilistic decision process mixed multinomial logit model: A warning on potential confounding. Transportation, 40(5), 1003-1020. https://doi.org/10.1007/s11116-012-9447-0.

Hess, S., Stathopoulos, A., Campbell, D., O'Neill, V., \& Caussade, S. (2013). It's not that I don't care, I just don't care very much: Confounding between attribute non-attendance and taste heterogeneity. Transportation, 40(3), 583-607. https://doi.org/10.1007/s11116-012-9438-1.

Hole, A. R. (2011). A discrete choice model with endogenous attribute attendance. Economics Letters, 110(3), 203-205. https://doi.org/10.1016/ j.econlet.2010.11.033.

Hole, A. R., Kolstad, J. R., \& Gyrd-Hansen, D. (2013). Inferred vs. stated attribute non-attendance in choice experiments: A study of doctors? Prescription behaviour. Journal of Economic Behavior \& Organization, 96 (December), 21-31. https://doi.org/10.1016/j.jebo.2013.09.009.

Holmqvist, Kenneth, ed. 2011. Eye tracking: A comprehensive guide to methods and measures. Oxford; New York: Oxford University Press. 
Kahneman, D., Knetsch, J. L., \& Thaler, R. H. (1991). Anomalies: The endowment effect, loss aversion, and status quo bias. Journal of Economic Perspectives, 5(1), 193-206. https://doi.org/10.1257/jep.5.1.193.

Karmarkar, U. R., Shiv, B., \& Knutson, B. (2015). Cost conscious? The neural and behavioral impact of price primacy on decision making. Journal of Marketing Research, 52(4), 467-481. https://doi.org/10.1509/jmr.13.0488.

Kjær, T., Bech, M., Gyrd-Hansen, D., \& Hart-Hansen, K. (2006). Ordering effect and price sensitivity in discrete choice experiments: Need we worry? Health Economics, 15(11), 1217-1228. https://doi.org/10.1002/hec.1117.

Knoepfle, D. T., Wang, J. T.-y., \& Camerer, C. F. (2009). Studying learning in games using eye-tracking. Journal of the European Economic Association, 7(2-3), 388-398. https://doi.org/10.1162/JEEA.2009.7.2-3.388.

Krucien, N., Ryan, M., \& Hermens, F. (2017). Visual attention in multi-attributes choices: What can eye-tracking tell us? Journal of Economic Behavior \& Organization, 135 (March), 251-267. https://doi.org/10.1016/j.jebo.2017.01.018.

Lahey, J. N., \& Oxley, D. (2016). The power of eye tracking in economics experiments. American Economic Review, 106(5), 309-313. https:// doi.org/10.1257/aer.p20161009.

Manski, C. F. (1977). The structure of random utility models. Theory and Decision, 8(3), 229-254. https://doi.org/10.1007/BF00133443.

Mantonakis, A., Rodero, P., Lesschaeve, I., \& Hastie, R. (2009). Order in choice: Effects of serial position on preferences. Psychological Science, 20(11), 1309-1312. https://doi.org/10.1111/j.1467-9280.2009.02453.x.

McFadden, D. (1974). Conditional logit analysis of qualitative choice behavior. In P. Zarembka (Ed.), Frontiers in econometrics (pp. 105-142). New York: Academic Press.

McIntosh, E., \& Ryan, M. (2002). Using discrete choice experiments to derive welfare estimates for the provision of elective surgery: Implications of discontinuous preferences. Journal of Economic Psychology, 23(3), 367-382. https://doi.org/10.1016/S0167-4870(02)00081-8.

McNair, B. J., Hensher, D. A., \& Bennett, J. (2012). Modelling heterogeneity in response behaviour towards a sequence of discrete choice questions: A probabilistic decision process model. Environmental and Resource Economics, 51(4), 599-616. https://doi.org/10.1007/ s10640-011-9514-6.

Meibner, M., Musalem, A., \& Huber, J. (2016). Eye tracking reveals processes that enable conjoint choices to become increasingly efficient with practice. Journal of Marketing Research, 53(1), 1-17. https://doi.org/10.1509/jmr.13.0467.

Payne, J. W., Bettman, J. R., \& Johnson, E. J. (1993). The adaptive decision maker. Cambridge ; New York, NY, USA: Cambridge University Press.

Rayner, K. (1978). Eye movements in reading and information processing. Psychological Bulletin, 85(3), 618-660.

Rayner, K. (1998). Eye movements in reading and information processing: 20 years of research. Psychological Bulletin, 124(3), $372-422$.

Reutskaja, E., Nagel, R., Camerer, C. F., \& Rangel, A. (2011). Search dynamics in consumer choice under time pressure: An eye-tracking study. American Economic Review, 101(2), 900-926. https://doi.org/10.1257/aer.101.2.900.

Rosenberger, R. S., Peterson, G. L., Clarke, A., \& Brown, T. C. (2003). Measuring dispositions for lexicographic preferences of environmental goods: Integrating economics, psychology and ethics. Ecological Economics, 44(1), 63-76. https://doi.org/10.1016/S0921-8009(02)00221-5.

Ryan, M., Yi, D., Avenell, A., Douglas, F., Aucott, L., van Teijlingen, E., \& Vale, L. (2015). Gaining pounds by losing pounds: Preferences for lifestyle interventions to reduce obesity. Health Economics, Policy, and Law, 10(2), 161-182. https://doi.org/10.1017/S1744133114000413.

Saelensminde, K. (2006). Causes and consequences of lexicographic choices in stated choice studies. Ecological Economics, 59(3), 331-340. https://doi.org/10.1016/j.ecolecon.2005.11.001.

Scarpa, R., Zanoli, R., Bruschi, V., \& Naspetti, S. (2013). Inferred and stated attribute non-attendance in food choice experiments. American Journal of Agricultural Economics, 95(1), 165-180. https://doi.org/10.1093/ajae/aas073.

Scott, A., \& Vick, S. (1999). Patients, doctors and contracts: An application of principal-agent theory to the doctor-patient relationship. Scottish Journal of Political Economy, 46(2), 111-134. https://doi.org/10.1111/1467-9485.00124.

Shimojo, S., Simion, C., Shimojo, E., \& Scheier, C. (2003). Gaze bias both reflects and influences preference. Nature Neuroscience, 6(12), 1317-1322. https://doi.org/10.1038/nn1150.

Shugan, S. M. (1980). The cost of thinking. Journal of Consumer Research, 7(2), 99. https://doi.org/10.1086/208799.

Spinks, J., \& Mortimer, D. (2015). Lost in the crowd? Using eye-tracking to investigate the effect of complexity on attribute non-attendance in discrete choice experiments. BMC Medical Informatics and Decision Making, 16(1), 14. https://doi.org/10.1186/s12911-016-0251-1.

Tatler, B. W., Baddeley, R. J., \& Vincent, B. T. (2006). The long and the short of it: Spatial statistics at fixation vary with saccade amplitude and task. Vision Research, 46(12), 1857-1862. https://doi.org/10.1016/j.visres.2005.12.005.

Train, K. (2009). Discrete choice methods with simulation (2nd ed.). Cambridge; New York: Cambridge University Press.

Uggeldahl, K., Jacobsen, C., Lundhede, T. H., \& Olsen, S. B. (2016). Choice certainty in discrete choice experiments: Will eye tracking provide useful measures? Journal of Choice Modelling, 20 (September), 35-48. https://doi.org/10.1016/j.jocm.2016.09.002.

van Belle, G. (2010). Fixation patterns during recognition of personally familiar and unfamiliar faces. Frontiers in Psychology, 1. https://doi. org/10.3389/fpsyg.2010.00020. 
Van Loo, E. J., Caputo, V., Nayga, R. M., Seo, H.-S., Zhang, B., \& Verbeke, W. (2015). Sustainability labels on coffee: Consumer preferences, willingness-to-pay and visual attention to attributes. Ecological Economics, 118 (October), 215-225. https://doi.org/10.1016/j. ecolecon.2015.07.011.

Viney, R., Savage, E., \& Louviere, J. (2005). Empirical investigation of experimental design properties of discrete choice experiments in health care. Health Economics, 14(4), 349-362. https://doi.org/10.1002/hec.981.

Wang, J. T.-y., Spezio, M., \& Camerer, C. F. (2010). Pinocchio's pupil: Using eyetracking and pupil dilation to understand truth telling and deception in sender-receiver games. American Economic Review, 100(3), 984-1007. https://doi.org/10.1257/aer.100.3.984.

\section{SUPPORTING INFORMATION}

Additional Supporting Information may be found online in the supporting information tab for this article.

How to cite this article: Ryan M, Krucien N, Hermens F. The eyes have it: Using eye tracking to inform information processing strategies in multi-attributes choices. Health Economics. 2017;1-13. https://doi.org/ $\underline{10.1002 / \text { hec. } 3626}$ 